\title{
XXIV. ON THE PHYSIOLOGY OF THE SILKWORM.
}

\author{
BY ALEXANDER PRINGLE JAMESON \\ AND WILLIAM RINGROSE GELSTON ATKINS. \\ (Published by permission of the Agricultural Adviser to the Government of India.)
}

(Received February 1\%th, 1921.)

The digestive enzymes of Lepidoptera and other invertebrates appear to warrant a closer study than has as yet been accorded to them, more especially on account of the prevailing alkalinity of the secretions. Those of the silkworm were investigated by Sawamura [1900-1902], a summary of whose work, together with that of earlier investigators, is given below. It seemed of interest however to examine some of the actions more fully with the aid of indicators, whereby the hydrogen ion concentration could be measured with very approximate accuracy according to the method as improved by Clark and Lubs [1917]. In this connection the recent publication with coloured plates by Clark [1920] proved specially useful.

At the outset it may be remarked that it seemed advisable to discard such terms as stomach, intestine, colon, etc. which have a definite physiological connotation and to rely upon purely morphological terms which have no misleading association with vertebrate physiology. Behind the mouth there is the fore-gut, a thin-walled short tube, with no digestive cells according to Sawamura. Then follows the mid-gut with an expanded anterior portion, "the stomach," and a narrower posterior region, "the intestine." Both these regions have cells which secrete digestive enzymes. Behind the mid-gut lies the hind-gut, a short tube with no digestive power. The Malpighian tubes enter at the junction between the mid-gut and the hind-gut.

According to Kellner [1887] the silkworm, Bombyx mori, digests albumin, fat and carbohydrates except cellulose. Jousset [1874] showed that in Blatta orientalis the middle intestine was acid. Krukenberg [1880] concluded that trypsin predominates over pepsin in Insecta and other Arthropoda. Biedermann [1898] demonstrated that in Tenebrio molitor (Coleoptera) the upper mid-gut is acid, and the lower alkaline. It digests albumin, fat, disaccharides and starch, but not cellulose, the albumin being split up to amino compounds.

Sawamura found that in alkaline solution, which is the natural reaction, the enzymes of the silkworm digest starch rapidly, also but more slowly fat, with liberation of free acid. Fibrin is slowly acted on and gives the biuret reaction after two days at $36^{\circ}$. Gelatin is liquefied and freshly precipitated 
caseinogen is dissolved. He concludes that tryptic, lipatic and diastatic enzymes are present, but that neither pepsin nor pepsinogen exists in the cells. The "intestine," namely the rear portion of the mid-gut, has a tryptic enzyme, but the others are absent. He further examined Caligula japonica Moor (Lepidoptera) and found that it contained a tryptic enzyme which gave peptones like pepsin, but in an alkaline solution. It differs from trypsin however in giving no amino-acids or tryptophan, the action stopping with the production of peptones. Starch was digested more slowly than by the silkworm as after six days at $36^{\circ}$ the reaction-mixture still contained erythrodextrin, though maltose was also present as shown by the osazone. The existence of a feebly acting maltase was demonstrated by the fact that fermentation of the products of digestion by means of Saccharomyces apiculatus Reess, gave a little carbon dioxide after a few days. Since this yeast is free from maltase it is obvious that the glucose must have been produced by the digestive juices of the silkworm.

The interest in these results lies in the fact that the medium is alkaline. Now though the amylase of the human mouth, ptyalin, acts in an almost neutral solution, yet the diastase of the stomach, of plants and of takadiastase preparation all act in acid solutions. Maltase moreover also acts in a neutral or faintly acid medium and is rendered inactive by a trace of alkali [Davis, 1916]. Yet in the insects mentioned these reactions are all in progress in an alkaline medium and cease when the reaction is made acid as Sawamura has shown.

It appeared of interest therefore to test for some of these enzymes taking into account the precise reaction of the medium.

\section{Hydrogen ion concentration of Bombyx mori.}

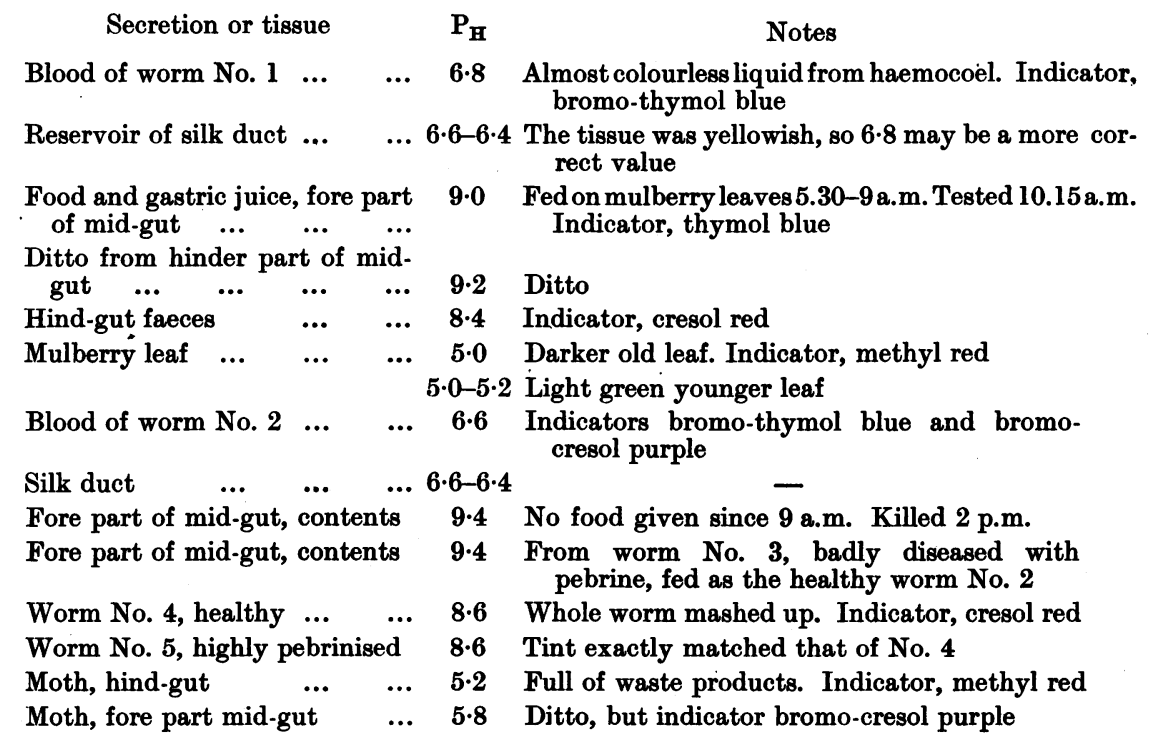


From the foregoing it may be seen that the blood is almost neutral, having only a very faint acidity. The silk duct and its reservoir, which project into the haemocoel, have almost the same reaction, the slightly higher acidity values recorded being due in part to error introduced by the natural yellow of this tissue. It should be remarked that the reactions were judged by mixing indicator and tissue or secretion on white porcelain and matching against Clark's coloured plates and drops of standard solutions of known $\mathbf{P}_{\mathbf{H}}$ value. The very definite strong alkalinity of the digestive secretions is clearly shown in both the normal and highly diseased worms; no alteration in this reaction could be found in the latter. The strong alkalinity decreases somewhat towards the posterior end of the alimentary canal. It is noteworthy that after the metamorphosis the reaction of the gut has changed from alkaline to a fair degree of acidity. This is apparently due to the loading of the gut with waste products, for the moth does not feed.

It was thought possible that the alkalinity of the digestive juice of the worm might be due to the slow liberation of ammonia by bacterial action. This was disproved however by the fact that in a worm starved for a day and fed for twenty minutes before being killed the fore part of the mid-gut was found full of liquid with an alkalinity $P_{\mathbf{H}}=9 \cdot 6-9 \cdot 8$. The hind part, with but little food in it, gave $P_{H}=9 \cdot 0$. Both portions of the mid-gut gave $P_{H}=9 \cdot 6-9 \cdot 8$ in a similar worm killed fasting.

There is thus no doubt that the acid mulberry leaf is rapidly neutralised by a highly alkaline digestive juice and that the breaking down of starch and disaccharides must be accomplished in an alkaline medium, though the best known amylases are inactive under these conditions.

Enzymes of the silkworm.

The rapidity with which the digestive juice acts on a $0.4 \%$ (approx.) solution of potato starch was shown by the following: 2 cc. of the starch solution diluted to $10 \mathrm{cc}$. mixed with three drops of the juice at $20^{\circ}$.

\begin{tabular}{|c|c|c|}
\hline $\begin{array}{l}\text { Time in } \\
\text { minutes }\end{array}$ & $\begin{array}{c}\text { Colour with iodine } \\
\text { solution }\end{array}$ & Notes \\
\hline $\mathbf{0}$ & Blue & $P_{H}=9.6$ for the diluted \\
\hline 2 & Blue & juice, no change in $P_{H}$ \\
\hline 5 & Purple & effected by dilution \\
\hline 6 & Brownish red & \\
\hline 7 & Faint reddish & \\
\hline 9 & Faint colour & \\
\hline 10 & No colour & \\
\hline
\end{tabular}

There is thus an active diastase in the secretion. The resulting solution reduced Fehling's solution.

Sawamura concluded that a feeble maltase was present in the secretion; our results are in agreement with this as after three drops of secretion had stood with $10 \mathrm{cc}$. of $0.16 \%$ maltose for 24 hours at about $20^{\circ}$ in presence of toluene it was found that of the control solution $48.4 \mathrm{cc}$. were required to reduce $10 \mathrm{cc}$. of Fehling's solution, whereas the solution with the secretion 
required only $44 \cdot 7$ cc. A feeble invertase action could be detected in the digestive secretion after 20 hours.

On testing this secretion with benzidine and with $\alpha$-naphthol no evidence of oxidase action could be found, nor was any shown on the addition of hydrogen peroxide, though a feeble catalase action was shown.

On testing the faintly yellowish liquid of the haemocoel, the "blood," no digestive action on starch could be observed, but the presence of invertase was demonstrated, also of a maltase of much the same degree of feeble activity as that shown by the digestive secretion of the mid-gut. No oxidase action was observed, even with the addition of hydrogen peroxide, but catalase action was found.

The carbohydrate metabolism of the silkworm appears therefore to begin with the digestion of starch and the further splitting up of part of the maltose formed in the mid-gut. The remainder of the cane sugar and maltose appears to be absorbed by the haemocoelic liquid and to be further broken up by it as required for metabolism. The "blood" shows no evidence of having a respiratory function as oxidases are absent. Respiration is provided for by the numerous tracheae found throughout the body of the worm.

\section{SUMmaRY.}

1. The blood of the silkworm, Bombyx mori, has a hydrogen ion concentration $\mathrm{P}_{\mathrm{H}}=6.8$ and that of the silk gland is very similar. The digestive secretion is strongly alkaline, for this $P_{H}=9 \cdot 0-9 \cdot 8$. The reaction of the hind-gut is less strongly alkaline, $P_{H}=8 \cdot 4$.

2. The gut of the moth is acid, $P_{H}=5 \cdot 2-5 \cdot 8$.

3. No difference could be detected between the $P_{H}$ values of the digestive secretions of normal and highly pebrinised worms, nor between their general body reaction.

4. A peculiar diastase is present in the digestive juice of the silkworm, which is active in strongly alkaline solution. A maltase is also present.

5. A feeble maltase and a more active invertase are present in the blood or haemocoelic fluid. Oxidases are absent from both blood and digestive juice, but catalase action is shown by both.

In conclusion we wish to acknowledge our indebtedness to the Director of the Agricultural Research Institute, Pusa, Behar, India, for facilities in carrying out this research.

\section{BIBLIOGRAPHY.}

Biedermann, W. (1898). Pflüger's Arch. 72, 105; cited from Chem. Centralblatt, 1898, 370.

Clark, W. M. (1920). The determination of hydrogen ions. Williams and Wilkins Co.

Clark, W. M. and Lubs, H. A. (1917). J. Bact. 2, 1, 109, 191.

Davis, W. A. (1916). Biochem. J. 10, 31.

Jousset (1874). Compt. Rend. 82, 97.

Kellner, O. with S. Kakizaki, M. Matsuoka and T. Yoshu (1887). Landw. Versuchs-stationen, 33, 381.

Krukenberg, C. Fr. W. (1880). Jahresber. Fort. Thier-Chemie, 10; cited from Unt. des physiol. Inst. der Univ. Heidelberg, 2, H. 3, 338-366.

Sawamura, S. (1900-1902). Bull. Coll. Agric. Tokyo, Imp. Univ. Japan, 4. 